\title{
Prevalence of Hypertension and Associated Factors among the Outpatient Department in Akaki Kality Subcity Health Centers, Addis Ababa, Ethiopia
}

\author{
Tadesse Bedada Haye (D) and Berhanu Tolera Agama \\ Addis Ababa University College of Health Sciences, Addis Ababa, Ethiopia \\ Correspondence should be addressed to Tadesse Bedada Haye; tadesse.bedada@aau.edu.et
}

Received 28 November 2019; Revised 23 April 2020; Accepted 4 August 2020; Published 18 August 2020

Academic Editor: Fulvio Morello

Copyright (C) 2020 Tadesse Bedada Haye and Berhanu Tolera Agama. This is an open access article distributed under the Creative Commons Attribution License, which permits unrestricted use, distribution, and reproduction in any medium, provided the original work is properly cited.

\begin{abstract}
Background. Fatalities from hypertension in East Africa are increasing, even though they decreased in western industrial regions. Older age, being female, illiterate, smoking, physical inactivity, and high waist circumferences are major risk factors for the development of hypertension. The prevalence of hypertension among Federal Ministry Civil servants in Addis Ababa, Ethiopia, has found to be high; which is an indication for institution-based hypertension-screening programs. Objective. Prevalence of hypertension and associated factors among the outpatient department in Akaki Kality Subcity Health Centers, Addis Ababa, Ethiopia. Methodology. Facility-based cross-sectional study was carried out on systematically sampled 401 out-department patients whose age was greater than or equal to 18 years in four government health centers in Addis Ababa. Data collection took place from March 10, 2018, to April 06 2018. Binary logistic regression analysis was carried out to identify predictors of hypertension. Results. Patients had a mean age of 41.17 years (95\% CI: 39.77-42.57). The prevalence of hypertension was $14 \%$ (95\% CI: 13.653-14.347), and 30 (53.57\%) were males. Alcohol drinkers were 11.844 times more likely to be hypertensive as compared to non-alcohol drinkers $(\mathrm{AOR}=11.844,95 \% \mathrm{CI}$ : 3.596-39.014). Cigarette smokers were 16.511 times more likely to be hypertensive as compared to non-cigarette smokers ( $\mathrm{AOR}=16.511,95 \% \mathrm{CI}: 4.775-57.084)$. Khat chewers were 6.964 times more likely to be hypertensive as compared to non-khat chewers (AOR $=6.964,95 \% \mathrm{CI}: 1.773-26.889)$. Conclusion. The prevalence of patients with hypertension was $14 \%$. Alcohol drinking, cigarette smoking, khat chewing, body mass index $\geq 25 \mathrm{~kg} / \mathrm{m}^{2}$, and age $\geq 44$ years old are major determinants identified by this study. Hence, appropriate management of patients focusing on the relevant associated factors would be of great benefit in controlling hypertension.
\end{abstract}

\section{Background}

Heart pumps blood around the body through blood vessels. Blood pressure is the force at which blood moves through these vessels [1]. Hypertension means systolic blood pressure greater than or equal to $140 \mathrm{mmhg}$ and/or diastolic pressure greater than or equal to $90 \mathrm{~mm}$ hg [2]. Thirty-five million people died from noncommunicable diseases in the world, and $80 \%$ of the deaths were in lower- and middle-income countries [3]. According to a study that was conducted in the USA, among 33,086 study participants, maternal alcohol drinking during pregnancy was associated with the development of hypertension [4]. Noncommunicable diseases, including hypertension, are the leading causes of death among adults in Addis Ababa together with the existing burden of communicable diseases [1].

In the United Arab Emirates, the prevalence of hypertension in a representative sample of young male South Asian immigrants living in the UAE was relatively high. However, the awareness, treatment, and control of hypertension within this population were very low [5]. Trends in blood pressure show an increase in systolic blood pressure in many sub-Saharan regions, and these are among the highest in the world [6].

One study that was conducted in Malawi, among 952 participants, showed the prevalence of hypertension was $23.7 \%$ [7]. The prevalence of hypertension is found to be 
high; prevention strategies are urgently needed to address this life-threatening and important risk factor for cardiovascular diseases including hypertension [8].

The fatalities from hypertension in East Africa are increasing even though they decreased in the western industrial regions [9].

Since cardiovascular disease is by far the largest cause of years of life lost in developing countries, the need for new approaches towards control of this major risk factor should be emphasized [10]. In South Africa, it was revealed that the prevalence of hypertension was found to be $77.3 \%$ among older adults [11].

Noncommunicable diseases, including hypertension, are the leading causes of death among adults in Addis Ababa, together with the existing burden of communicable diseases [8].

Based on some studies, male sex, overweight, and sleeping $<5$ hours per day were the common factors for the development of hypertension [12-14]. In addition, male sex, having a family history of hypertension, inadequate physical activity, low consumption of vegetables, excess salt consumption, and obesity were among the factors [15].

Bankers and teachers in Addis Ababa had the prevalence of $21 \%$ hypertension, whereas community in Northwest Ethiopia had 27.9\% [16, 17]. Urban communities and female gender are more affected by hypertension compared to rural communities and male gender, respectively [17]. The prevalence of hypertension among university students was $7.7 \%$ and recorded as the lowest prevalence of the studies [18].

Even though evidence shows high prevalence and different risk factors at different parts of the world as well as in Ethiopia, there are inadequate studies in Addis Ababa regarding hypertension and its determinants. Therefore, this study aimed to collect and organize the data about prevalence of hypertension and associated factors.

\section{Methods}

2.1. Study Area and Period. The study was conducted among outpatients in Akaki Kality Subcity four governmental health enters from March 10, 2018, to April 06 2018. There are seven government-owned and one nongovernmental health centers in the subcity.

Study design: institutional-based descriptive cross-sectional study design was used.

2.2. Populations. Target population: outpatient department attendants at the health center found in Akaki Kality Subcity.

Study population: outpatient department attendants from the four health centers in Akaki Kality Subcity.

2.3. Inclusion and Exclusion Criteria. Inclusion criteria: all adult outpatient department attendants.

Exclusion criteria: severe ill patients who were not able to respond.
2.4. Sampling Size Calculation and Sampling Procedure. The sample size was calculated using the formula for a single population proportion. Systematic sampling was used to select the size proportionate sample from each selected health center. Four health centers out of the seven were selected for the study. The total number of patients in four health centers during the study was 9246 .

To calculate the sample size, according to the study that was conducted in Addis Ababa among the Federal Ministry of Civil servants in 2014, the proportion of hypertension was $27.3 \%$ and then $P=0.0273, d=0.05$, confidence level $=95 \%$, $n=((Z \alpha / 2) p q) / d^{2}=\left(1.96^{2} \times 0.273 \times 0.727\right) / 0.0 .05^{2}=305$.

The average risk factor of hypertension (smokers- $53 \%$, alcohol drinking-32.9\%, and khat chewing-35.8\%) was $40.57 \%$.

$P=0.4057, \quad q=1-p=1-0.4057=0.5943 ; \quad$ then, $n=\left(Z_{\alpha / 2}\right)^{2}{ }_{P q / d}{ }^{2}=(1.96)^{2} \quad(0.4057 \times 0.5943) /(0.05)^{2}=370$. Then, by adding $10 \%$ of nonresponse rate gives 407 , which was the final sample size. To get the sampling interval, $9246 / 407=23$; then, $K$ is 23 . Therefore, the study participants were selected every 23 intervals.

2.5. Study Variables. Dependent variable: prevalence of hypertension.

Independent variables: sociodemographic characteristics, alcohol consumption, khat chewing, cigarette smoking, and body mass index.

2.6. Data Collection Techniques. Face-to-face interview of the patients about sociodemographic characteristics, consisting of age, sex, marital status, income, and occupational status, was conducted by a trained interviewer. The questionnaires were adopted from the WHO STEPwise survey and included additional information. Moreover, blood pressure was measured using a manual sphygmomanometer and stethoscope, weight by using the adult weight scale, and height by using a tape meter. The questionnaires were prepared in English language and then translated into Amharic language and back-translated to English to check its consistency.

2.7. Data Processing and Analysis. The principal investigators cleaned and repeatedly checked data and entered the collected data to Epi Info version 7 for further organizing and processing. Then, data were transformed to SPSS version 20 in order to analyze them. Descriptive statistics, such as mean, median, and standard deviation, were calculated. Binary logistic regression was used to identify factors associated with hypertension. Lastly, the findings were organized, interpreted, and narrated accordingly.

2.8. Data Quality Control. The principal investigators checked the data during collection and analysis to ensure that all the information was properly collected and recorded. In addition, the information was checked again for completeness and internal consistency. 


\subsection{Operational Definitions}

Alcohol consumptions: drinking greater than 30 grams of ethanol per day

Hypertension: systolic blood pressure $\geq 140 \mathrm{mmHg}$ and or/diastolic blood pressure $\geq 90 \mathrm{mmHg}$

Moderate drink of alcohol: two drinks a day for men $<65$ years old or one drink a day for age $>65$ years and women

One drink of alcohol: $355 \mathrm{ml}$ of beer or $148 \mathrm{ml}$ of wine or $1.5 \mathrm{ml}$ of sprite

Physical activity: walking, jogging, swimming, and cycling at least 30 minutes per day

\section{Results}

Four hundred and one outpatient department attendants (with a response rate of $98.53 \%$ ) participated in this study. The respondents were selected from four health centers found in Akaki Kality subcity of Addis Ababa City Administration.

A majority of the respondents were urban dwellers (381, 95\%). Two hundred and thirty-one (57.6\%) were females. Their mean age was 41.17 years (95\% CI: $39.77-42.57)$. Three hundred and seven (76.6\%) participants were Orthodox Christianity followers. One hundred and seventy-two (42.9\%) respondents were Oromo ethnic group. Two hundred and seventy (67.3\%) of them were married, and 113 $(28.2 \%)$ were educated to the level of grade 1 to grade 8 . One hundred and nine (27.2\%) participants were government employees, and their mean monthly income was 2712.68 birr (95\% CI: 2493.9-2931.46) (Table 1).

3.1. Anthropometric Values and Behavioral Characteristics of the Study Subjects. Mean value of weight, height, and body mass index of the participants was $67 \mathrm{~kg}$ (95\% CI: 65.84-68.16), 1.65 meters (95\% CI: 1.646-1.654), and $24.27 \mathrm{~kg} / \mathrm{m}^{2}$ (95\% CI: 23.93-24.61), respectively.

About forty-nine (12.2\%) of participants smoke cigarettes, and twenty-five $(6.2 \%)$ of them smoke one pack of cigarettes per day. One hundred and fifty-one (37.7\%) and forty-five (11.2\%) study participants drink alcohol and one drink weekly, respectively. Forty-four (11\%) chew khat, and fifteen $(3.7 \%)$ of them chewed khat daily. One hundred and ninety $(47.7 \%)$ of study participants were practicing regular exercise, and one hundred and forty-six (36.4\%) of study participants said walking was considered as a regular exercise (Table 2).

3.2. Status of Hypertension among Study Participants. The mean systolic blood pressure and diastolic blood pressure of study participants were $120.88 \mathrm{mmHg} \quad(95 \% \quad \mathrm{CI}$ : 119.26-122.50) and $79.87 \mathrm{mmHg}$ (95\% CI: 79.01-80.73), respectively. The overall prevalence of hypertension among study participant was 14\% (95\% CI: 13.653-14.347). Accordingly, ten $(2.5 \%)$ outpatient department attendants have isolated systolic hypertension $(\geq 140 /<90 \mathrm{mmHg})$, eight $(2 \%)$
TABLe 1: Sociodemographic characteristics of the study subjects, Akaki Kality, Addis Ababa, Ethiopia, 2018.

\begin{tabular}{|c|c|c|}
\hline Characteristic & Women, $n(\%)$ & Men, $n(\%)$ \\
\hline \multicolumn{3}{|l|}{ Place of residence } \\
\hline Rural & $12(5.2)$ & $8(4.7)$ \\
\hline Urban & $219(94.8)$ & $162(95.3)$ \\
\hline \multicolumn{3}{|l|}{ Age, year } \\
\hline$\leq 24$ & $28(12.1)$ & $21(12.4)$ \\
\hline $25-34$ & $65(28.1)$ & $37(21.8)$ \\
\hline $35-44$ & $61(26.4)$ & $42(24.7)$ \\
\hline $45-54$ & $43(18.6)$ & $27(15.9)$ \\
\hline $55-64$ & $21(9.1)$ & $24(14.1)$ \\
\hline$\geq 65$ & $13(5.6)$ & $19(11.2)$ \\
\hline Mean & 41.17 & \\
\hline \multicolumn{3}{|l|}{ Religion } \\
\hline Orthodox & $178(77.7)$ & $129(76.8)$ \\
\hline Muslim & $23(10)$ & $22(13.1)$ \\
\hline Protestant & $27(11.8)$ & $13(7.7)$ \\
\hline Catholic & $1(0.4)$ & $4(2.4)$ \\
\hline Others & $2(0.1)$ & $0(0)$ \\
\hline \multicolumn{3}{|l|}{ Ethnicity } \\
\hline Oromo & $100(43.3)$ & $72(44.4)$ \\
\hline Amhara & $73(31.6)$ & $59(34.7)$ \\
\hline Tigre & $33(14.3)$ & $19(11.2)$ \\
\hline Guraghe & $21(9.1)$ & $14(8.2)$ \\
\hline Others & $4(1.7)$ & $6(1.5)$ \\
\hline \multicolumn{3}{|l|}{ Marital status } \\
\hline Single & $22(9.5)$ & $26(15.3)$ \\
\hline Married & $144(62.3)$ & $126(74.1)$ \\
\hline Widowed & $34(14.7)$ & $6(3.5)$ \\
\hline Divorced & $25(10.8)$ & $7(4.1)$ \\
\hline Separated & $11(2.7)$ & $5(2.9)$ \\
\hline \multicolumn{3}{|l|}{ Educational status } \\
\hline Cannot read and write & $32(13.9)$ & $8(4.7)$ \\
\hline Only read and write & $23(10)$ & $20(11.8)$ \\
\hline Grade $1-8$ & $66(28.6)$ & $47(27.6)$ \\
\hline Grade 9-12 & $46(19.9)$ & $45(26.5)$ \\
\hline Diploma & $51(22.1)$ & $28(16.5)$ \\
\hline First degree and above & $13(5.6)$ & $22(12.9)$ \\
\hline \multicolumn{3}{|l|}{ Occupational status } \\
\hline Government employee & $64(29.8)$ & $45(31)$ \\
\hline Merchant & $38(17.7)$ & $31(21.4)$ \\
\hline Private employee & $58(27)$ & $59(40.7)$ \\
\hline Jobless & $36(16.7)$ & $9(6.2)$ \\
\hline House wife & $19(8.8)$ & $1(0.7)$ \\
\hline \multicolumn{3}{|l|}{ Monthly income, birr } \\
\hline$<600$ & $45(19.5)$ & $18(10.6)$ \\
\hline $600-2000$ & $98(42.4)$ & $74(43.5)$ \\
\hline $2001-4000$ & $47(20.3)$ & $29(17.1)$ \\
\hline $4001-6000$ & $20(8.7)$ & $24(14.1)$ \\
\hline$>6000$ & $21(9.1)$ & $25(14.7)$ \\
\hline Mean & 271 & \\
\hline
\end{tabular}

have isolated diastolic hypertension $(<140 / \geq 90 \mathrm{mmHg}), 33$ $(8.3 \%)$. Concerning the stage of hypertension, eighteen $(4.5 \%)$ of study participants have stage I hypertension, and four (1\%) of them have stage II hypertension (Table 3).

3.3. Factors Associated with Prevalence of Hypertension. In bivariate analysis, weight of study participants was significantly associated with hypertension $(\mathrm{OR}=1.082$; CI: 
TABLE 2: Anthropometric values and behavioral characteristics of study subjects, Akaki Kality, Addis Ababa, Ethiopia, 2018.

\begin{tabular}{|c|c|c|}
\hline Variable & Women, $n(\%)$ & Men, $n(\%)$ \\
\hline \multicolumn{3}{|l|}{ Weight, kg } \\
\hline$\leq 54$ & $39(17.2)$ & $16(9.4)$ \\
\hline $55-64$ & $60(26.4)$ & $39(22.9)$ \\
\hline$\geq 65$ & $128(56.4)$ & $115(67.6)$ \\
\hline Mean & 67.03 & \\
\hline Median & 67 & \\
\hline \multicolumn{3}{|l|}{ Height in meters } \\
\hline$\leq 1.54$ & $41(17.7)$ & $9(5.3)$ \\
\hline $1.55-1.64$ & $72(31.2)$ & $21(12.4)$ \\
\hline$\geq 1.65$ & $118(51.1)$ & $140(82.4)$ \\
\hline Mean & 1.65 & \\
\hline Median & 1.68 & \\
\hline \multicolumn{3}{|l|}{ Body mass index, $\mathrm{kg} / \mathrm{m}^{2}$} \\
\hline$<18.5$ & $10(4.3)$ & $9(5.3)$ \\
\hline $18.5-25$ & $128(55.4)$ & $102(60)$ \\
\hline$\geq 25$ & $93(40.3)$ & $59(34.7)$ \\
\hline Mean & 24.27 & \\
\hline Median & 24.30 & \\
\hline \multicolumn{3}{|l|}{ Cigarette smoking } \\
\hline Yes & $76(32.9)$ & $75(44.1)$ \\
\hline No & $155(67.1)$ & $95(55.9)$ \\
\hline \multicolumn{3}{|l|}{ Amount of smoking } \\
\hline$<1$ pack per day ${ }^{\circ}$ & $7(35)$ & $11(39.3)$ \\
\hline Only 1 pack per day & $11(55)$ & $14(50)$ \\
\hline 2 packs per day & $2(10)$ & $2(7.1)$ \\
\hline$\geq 3$ packs per day & 0 & $1(3.6)$ \\
\hline \multicolumn{3}{|l|}{ Alcohol drinking } \\
\hline Yes & $20(8.7)$ & $29(17.1)$ \\
\hline No & $211(91.3)$ & $141(82.9)$ \\
\hline \multicolumn{3}{|c|}{ Amount of alcohol drinking } \\
\hline$<1$ drink per day & $2(2.8)$ & $9(11.1)$ \\
\hline Only 1 drink per day & $19(26.4)$ & $26(32.1)$ \\
\hline$>1$ drink per day & $51(70.8)$ & $46(56.8)$ \\
\hline \multicolumn{3}{|l|}{ Khat chewing } \\
\hline Yes & $20(8.7)$ & $24(14.1)$ \\
\hline No & $211(91.3)$ & $146(85.9)$ \\
\hline \multicolumn{3}{|c|}{ Frequency of khat chewing } \\
\hline Sometimes per week & $11(57.9)$ & $15(55.6)$ \\
\hline Daily & $6(31.6)$ & $9(33.3)$ \\
\hline 2 times daily & 0 & $1(3.7)$ \\
\hline$\geq 3$ times daily & $2(10.5)$ & $2(7.4)$ \\
\hline \multicolumn{3}{|l|}{ Practicing regular exercise } \\
\hline Yes & $103(44.6)$ & $87(51.2)$ \\
\hline No & $128(55.4)$ & $83(48.8)$ \\
\hline \multicolumn{3}{|c|}{ Walking as a regular exercise } \\
\hline Yes & $83(35.9)$ & $63(37.1)$ \\
\hline No & $148(64.1)$ & $107(62.9)$ \\
\hline \multicolumn{3}{|c|}{ Running as a regular exercise } \\
\hline Yes & $14(6.1)$ & $13(7.6)$ \\
\hline No & $217(93.9)$ & $157(92.4)$ \\
\hline \multicolumn{3}{|c|}{ Jogging as a regular exercise } \\
\hline Yes & $7(3)$ & $11(6.5)$ \\
\hline No & $224(97)$ & $159(93.5)$ \\
\hline \multicolumn{3}{|c|}{ Swimming as a regular exercise } \\
\hline Yes & $5(2.2)$ & $2(1.2)$ \\
\hline No & $226(97.8)$ & $168(98.8)$ \\
\hline
\end{tabular}

TABLE 3: Status of hypertension in the study populations, Akaki Kality, Addis Ababa, Ethiopia, 2018.

\begin{tabular}{lcc}
\hline Variable & Women, $n(\%)$ & Men, $(n \%)$ \\
\hline Systolic blood pressure, mmHg & $2(0.9)$ & $0(0)$ \\
$\quad<90$ & $205(88.7)$ & $148(87.1)$ \\
$90-139$ & $24(10.4)$ & $22(12.9)$ \\
$\geq 140$ & \multicolumn{2}{c}{120.88} \\
$\quad$ Mean & \multicolumn{2}{c}{120} \\
$\quad$ Median & 0 & 0 \\
Diastolic blood pressure, mmHg & $209(90.5)$ & $148(87.1)$ \\
$\quad<60$ & $22(9.5)$ & $22(12.9)$ \\
$60-89$ & \multicolumn{2}{c}{79.87} \\
$\quad \geq 90$ & \multicolumn{3}{c}{80} \\
$\quad$ Mean & $26(11.3)$ & $30(17.6)$ \\
$\quad$ Median & $6(2.6)$ & $4(2.4)$ \\
Prevalence of hypertension & $4(1.7)$ & $4(2.4)$ \\
$\quad$ Total & \multicolumn{3}{c}{} \\
Type of hypertension & $15(6.5)$ & $18(10.6)$ \\
$\quad$ Isolated systolic & $9(3.9)$ & $10(17)$ \\
Isolated diastolic & $2(0.9)$ & $2(1.2)$ \\
Stage of hypertension &
\end{tabular}

1.051-1.113) $(P \leq 0.001)$. However, height of study participants was not significantly associated with hypertension $(P=0.829)$. Body mass index of study participants was significantly associated with hypertension $(P \leq 0.001)$. Alcohol drinkers were 32.303 times risky for hypertension than nondrinkers $\quad(\mathrm{OR}=32.303,95 \% \quad \mathrm{CI}: \quad 11.379-91.702$, $P \leq 0.001)$. Cigarette smokers were 93.33 times risky for hypertension compared to nonsmokers ( $\mathrm{OR}=93.33,95 \%$ CI: 38.713-225, $P \leq 0.001$ ).

Khat chewers were 43.57 times risky for hypertension when compared to non-chat chewers $(\mathrm{OR}=43.57,95 \% \mathrm{CI}$ : $19.52-97.21, P \leq 0.001)$. Study participants practicing regular exercise were 1.137 times risky for hypertension as compared to those who practiced it regularly $(\mathrm{OR}=1.137$, 95\% CI: $0.644-2, P=0.658$ ). In the multivariate logistic regression analysis, drinking alcohol, cigarette smoking, khat chewing, body mass index, and age were significantly associated with the development of hypertension $(P<0.05)$. Accordingly, alcohol drinkers were 11.844 times more likely to be hypertensive as compared to non-alcohol drinkers $(\mathrm{AOR}=11.844,95 \% \mathrm{CI}$ : 3.596-39.014). Cigarette smokers were 16.511 times more likely to be hypertensive as compared to non-cigarette smokers ( $\mathrm{AOR}=16.511,95 \% \mathrm{CI}$ : 4.775-57.084). Khat chewers were 6.905 times more likely to be hypertensive as compared to non-khat chewers $(\mathrm{AOR}=6.905,95 \% \mathrm{CI}: 1.773-26.889)($ Table 4$)$.

\section{Discussion}

Hypertension is becoming one of the major noncommunicable diseases in Ethiopia. It contributes significantly to high burden of heart diseases [17]. In this study, the 
TABLE 4: Factors affecting hypertension (bivariate and multivariate analyses), Akaki Kality, Addis Ababa, Ethiopia, 2018.

\begin{tabular}{|c|c|c|c|c|c|c|c|c|}
\hline \multirow{2}{*}{ Variable } & \multirow{2}{*}{$\beta$} & \multirow{2}{*}{ SE } & \multicolumn{2}{|c|}{$P$} & \multicolumn{2}{|c|}{ OR } & \multicolumn{2}{|c|}{$95 \% \mathrm{CI}$ for $\mathrm{AOR}$} \\
\hline & & & Crude & Adjusted & COR & AOR & Lower & Upper \\
\hline $\begin{array}{l}\text { Alcohol drinking-yes } \\
\text { No (reference) }\end{array}$ & 2.472 & 0.608 & 0.001 & 0.001 & 32.30 & 11.844 & 3.596 & 39.014 \\
\hline $\begin{array}{l}\text { Cigarette smoking-yes } \\
\text { No (reference) }\end{array}$ & 2.804 & 0.633 & 0.001 & 0.001 & 93.33 & 16.511 & 4.775 & 57.084 \\
\hline $\begin{array}{l}\text { Khat chewing-yes } \\
\text { No (reference) }\end{array}$ & 1.932 & 0.694 & 0.001 & 0.005 & 43.57 & 6.905 & 1.773 & 26.889 \\
\hline $\begin{array}{l}\text { BMI }\left(\mathrm{kg} / \mathrm{m}^{2}\right)>25 \\
<18.5 \text { (reference) }\end{array}$ & 0.277 & 0.071 & 0.001 & 0.001 & 1.404 & 1.320 & 1.149 & 1.516 \\
\hline $\begin{array}{l}\text { Age }>44 \text { years } \\
<35 \text { years (reference) }\end{array}$ & 0.039 & 0.018 & 0.001 & 0.028 & 1.051 & 1.040 & 1.004 & 1.077 \\
\hline
\end{tabular}

overall prevalence of hypertension among outpatient attendants was $14.0 \%$. It was almost similar with previous studies done in China (16.5\%), Northwest Ethiopia (13.3\%), and Addis Ababa (14.9\%) [19-21]. However, this finding is higher than the study done in Gondar University, Ethiopia (7.7\%). The reasons for low prevalence of hypertension among university students were low age distribution (mean 21 years), high prevalence of underweight (35.6\%), and low body mass index (mean $19.8 \mathrm{~kg} / \mathrm{m}^{2}$ ) [22].

The prevalence of hypertension among study participants is lower than studies done in Addis Ababa (27.3\%), Kenya, Nairobi (29.4\%), Bahir Dar (25.1\%), Durame town in Ethiopia (22.4\%), Northwest Ethiopia (27.9\%), and many others. This could be because one of the previous studies used multistage sampling procedure to collect study participants [23]. The other possible differences were older age and large sample sizes in previous studies [24, 25].

Increased age was identified as a factor for hypertension in this study and other studies $[5,23,26]$. This could be due to physiological change of blood vessels as the age increases.

Unlike many other studies [20, 22, 27, 28], this finding did not reveal any association of hypertension with weight. This could be due to difference in the study population, setting, sample size, and socioeconomic and cultural differences between the study participants.

In this study, outpatient attendants who have been drinking alcohol were 11.844 times more likely to be hypertensive as compared to those who have not been drinking alcohol. It was similar with the studies conducted in Gondar in Ethiopia and other parts of the world [22, 23, 29]. The possible reasons are that alcohol can produce central nervous system imbalance (initiates both central and peripheral reactions which lead to hypertension), baro reflex impairment (baroreflex challenged vasoconstrictors such as phenyl-epiphrine and angiotensin II), sympathetic out flow (causes secretion of corticotrophin releasing hormones (mineralo-corticostroid and catecholamines)), rennin-angiotensin system initiation, expansion of extracellular fluid (elevation of plasma vasopressin and rennin activities), and then shifts extracellular calcium to intracellular space by increasing sensitivity to vasoconstrictor nor-epinephrine. These all lead to vasoconstriction and cause hypertension [12-15, 29].

History of smoking is one of the well-established risk factors for hypertension [12]. Similarly, in this study, smokers were 16.511 times more likely to be hypertensive as compared to nonsmokers. This study is similar with studies that were conducted in different parts of the world, including Ethiopia [14, 30-32]. Cigarette smoking causes activation of the sympathetic nervous system and oxidative stress associated with increase markers of inflammation leading to endothelial dysfunction, vascular injury, plague progression, and increased arterial stiffness leading to the development of hypertension [33-35]. Many researchers have reported that cigarette smoking is positively associated with hypertension $[11,21,25,36-38]$, which is similar to the result of our study that revealed cigarette smoking was significantly associated with hypertension. The possible reason might be that cigarette smoking increases arterial inflammation and stiffness [29].

According to this study, khat chewers were 6.964 times at risk for hypertension than non-khat chewers. Others study also confirmed positive association between khat chewing and development of hypertension [29, 39]. The possible reason for this association is that khat contains a chemical called cathinone, which is a potent vasoconstrictor that causes diastolic blood pressure elevation. This is the reason why khat chewers were more likely to be hypertensive when compared with non-khat chewers [40].

\section{Conclusion}

In conclusion, the proportion of patients with hypertension was considerably high (14\%), which is higher than reports from many countries. The findings obtained from multivariate logistic regression analysis suggest that hypertension was associated with age $\geq 44$ years old, body mass index $\geq 25 \mathrm{~kg} / \mathrm{m}^{2}$, alcohol drinking, cigarette smoking, and khat chewing. Hence, appropriate management of patients focusing on the relevant associated factors identified for control of hypertension, which are modifiable factors, remains the mainstay to maintain control of hypertension.

\section{Data Availability}

The data that support the findings of this study are available on request from the corresponding author. 


\section{Ethical Approval}

Ethical clearance was obtained from the ethical clearance committee of Addis Ababa University, College of Public Health. Letter of cooperation was written from Addis Ababa University, School of Public Health, and disseminated to Akaki Kality subcity and then to selected health centers.

\section{Consent}

The study participants' participation was voluntary, and written consent was obtained. Name of the participant was omitted from the questionnaire; instead, the authors used the code number to confirm confidentiality.

\section{Conflicts of Interest}

The authors declare no conflicts of interest.

\section{Authors' Contributions}

BT and TB conceived the study and were involved in the design, field work, data analysis and interpretation, report writing, and manuscript preparation. In addition, TB drafted the manuscript.

\section{Acknowledgments}

The authors acknowledge Addis Ababa University for the ethical approval of this study. They are also thankful to the study participants for their voluntary participation.

\section{References}

[1] F. M. o. Health, "Protocol for the identification and management of hypertension in adults," Heathy Heart Africa, pp. 1-23, 2016.

[2] O. V. Adeniyi, P. Yogeswaran, B. Longo-Mbenza, and D. Ter Goon, "Uncontrolled hypertension and its determinants in patients with concomitant type 2 diabetes mellitus (T2DM) in rural South Africa," PLoS One, vol. 11, no. 3, Article ID e0150033, 2016.

[3] B. Hu, X. Liu, S. Yin, S. Fan, F. Feng, and J. Yuan, "Effects of psychological stress on hypertension in middle-aged Chinese: a cross-sectional study," PLoS One, vol. 10, no. 6, Article ID e0129163, 2015.

[4] I. S. K. Krishnadath, V. W. V. Jaddoe, L. M. Nahar-van Venrooij, and J. R. Toelsie, "Ethnic differences in prevalence and risk factors for hypertension in the suriname health study: a cross sectional population study," Population Health Metrics, vol. 14, no. 1, pp. 2-11, 2016.

[5] F. Bonsa, E. K. Gudina, and K. W. Hajito, "Prevalence of hypertension and associated factors in Bedele town, southwest Ethiopia," Ethiopian Journal of Health Sciences, vol. 24, no. 1, pp. 21-26, 2014.

[6] Y. J. Xie, S. C. Ho, X. Su, and Z.-M. Liu, "Changes in body weight from young adulthood to middle age and its association with blood pressure and hypertension: a cross-sectional study in Hong Kong Chinese women," Journal of American Heart Associatio, vol. 5, no. 1, pp. 1-10, 2016.

[7] S. T. Ntuli, E. Maimela, M. Alberts, S. Choma, and S. Dikotope, "Prevalence and associated risk factors of hypertension amongst adults in a rural community of Limpopo province, South Africa," African Journal of Primary Health Care \& Family Medicine, vol. 7, no. 1, pp. 1-5, 2015.

[8] A. Misganaw, D. H. Mariam, and T. Araya, "The double mortality burden among adults in Addis Ababa, Ethiopia, 2006-2009," Preventing Chronic Disease, vol. 9, pp. 1-10, 2012.

[9] C. Koebnick, M. H. Black, J. Wu et al., "The prevalence of primary pediatric prehypertension and hypertension in a realworld managed care system," The Journal of the American Society of Hypertension, vol. 15, no. 11, pp. 783-792, 2013.

[10] N. Lionakis, S. Elias, G. Favatas, and M. Georgopoulou, "Hypertension in the elderly," World Journal of Cardiology, vol. 4, no. 5, pp. 135-147, 2012.

[11] J.-C. Liu, Y.-P. Hsu, and S.-Y. Wu, "Statins and renin angiotens in system inhibitors dose-dependently protect hypertensive patients against dialysis risk," PLoS One, vol. 11, no. 9, Article ID e0162588, 2016.

[12] K. Husain, R. A. Ansari, and L. Ferder, "Alcohol-induced hypertension: mechanism and prevention," World Journal of Cardiology, vol. 6, no. 5, pp. 245-252, 2014.

[13] C. D. Parry, J. Patra, and J. Rehm, "Alcohol consumption and non-communicable diseases: epidemiology and policy implications," Addiction, vol. 106, no. 10, pp. 1718-1724, 2012.

[14] L. A. Colangelo, T.-H. T. Vu, M. Szklo, G. L. Burke, C. Sibley, and K. Liu, "Is the association of hypertension with cardiovascular events stronger among the lean and normal weight than among the overweight and obese?" Hypertension, vol. 66, no. 2, pp. 286-293, 2015.

[15] F. Nuwaha and G. Musinguzi, "Pre-hypertension in Uganda: a cross-sectional study," BMC Cardiovascular Disorders, vol. 13, no. 1, pp. 1-7, 2013.

[16] O. H. Divala, A. Amberbir, and Z. Ismail, "The burden of hypertension, diabetes mellitus, and cardiovascular risk factors among adult Malawians in HIV care: consequences for integrated services," BMC Public Health, vol. 16, no. 1, pp. 2-11, 2016.

[17] WHO, Stepwise Approach to Chronic Disease Risk Factor Surveillance, WHO, Geneva, Switzerland, 2005.

[18] K. Peltzer and N. Phaswana-Mafuya, "Hypertension and associated factors in older adults in South Africa," Cardiovascular Journal of Africa, vol. 24, no. 3, pp. 67-72, 2013.

[19] C. S. QianRen, H. Wang, Z. Wang, Z. Du, and B. Zhang, "Prospective study of optimal obesity index cut-off values for predicting incidence of hypertension in 18-65-year-old Chinese," PLoS One, vol. 11, no. 3, Article ID e0148140, 2016.

[20] B. Moges, B. Amare, B. Fantahun, and A. Kassu, "High prevalence of overweight, obesity, and hypertension with increased risk to cardiovascular disorders among adults in northwest Ethiopia: a cross sectional study," BMC Cardiovasc Disorders, vol. 14, no. 1, p. 9, 2014.

[21] L. D. Nshisso, A. Reese, B. Gelaye, S. Lemma, L. Berhane, and M. A. Williams, "Prevalence of hypertension and diabetes among Ethiopian adults," Diabetes \& Metabolic Syndrome: Clinical Research \& Reviews, vol. 6, no. 1, pp. 36-41, 2012.

[22] T. Tadesse and H. Alemu, "Hypertension and associated factors among university students in Gondar, Ethiopia: a cross-sectional study," BMC Cardiovasc Disorders, vol. 14, no. 937, p. 5, 2014.

[23] K. Angaw, A. K. Dadi, and K. A. Alene, "Prevalence of hypertension among federal ministry civil servants in Addis Ababa, Ethiopia: a call for a workplace-screening program," BMC Cardiovascular Disorders, vol. 15, no. 1, pp. 1-6, 2015.

[24] T. P. Helelo, Y. A. Gelaw, and A. A. Adane, "Prevalence and associated factors of hypertension among adults in Durame 
town, southern Ethiopia," PLoS One, vol. 9, no. 11, Article ID e112790, 2014.

[25] B. Olack, F. Wabwire-Mangen, L. Smeeth, J. M. Montgomery, N. Kiwanuka, and R. F. Breiman, "Risk factors of hypertension among adults aged 35-64 years living in an urban slum Nairobi, Kenya," BMC Public Health, vol. 15, no. 1, p. 9, 2015.

[26] S. Vijver, "Status report on hypertension in Africa," in Proceedings of the Consultative Review for the 6th Session of the African Union Conference of Ministers of Health on NCD's Panafrical Medical Journal, Addis Ababa, Ethiopia, 2013.

[27] G. Fikadu and S. Lemma, "Socioeconomic status and hypertension among teachers and Bankers in Addis Ababa, Ethiopia," International Journal of Hypertension, vol. 2016, Article ID 4143962, 7 pages, 2016.

[28] F. Tesfaye, P. Byass, and S. Wall, "Population based prevalence of highblood pressure among adults in Addis Ababa: uncovering a silent epidemic," BMC Cardiovascular Disorders, vol. 9, no. 1, p. 10, 2009.

[29] M. Fikru Tesfaye, P. Byass, S. Wall, Y. Berhane, and R. Bonita, "Association of smoking and khat (Catha edulis Forsk) use with high blood pressure among adults in Addis Ababa, Ethiopia, 2006," Centers for Disease Control and Prevention, vol. 5, no. 3, p. 11, 2008.

[30] S. M. Engel, E. Scher, S. Wallenstein et al., "Maternal active and passive smoking and hypertensive disorders of pregnancy," Epidemiology, vol. 24, no. 3, pp. 1-15, 2013.

[31] L. L. De Jonge, H. R. Harris, J. W. Rich-Edwards et al., "Parental smoking in pregnancy and the risks of adult onset hypertension," Hypertension, vol. 61, no. 2, pp. 494-500, 2013.

[32] A. Linneberg, R. K. Jacobsen, T. Skaaby et al., "Effect of smoking on blood pressure and resting heart rate: a mendelian randomisation meta-analysis in the CARTA consortium," Circulation: Cardiovascular Genetics, vol. 8, no. 6, pp. 832841, 2016.

[33] J. W. Kim, C. G. Park, S. J. Hong et al., "Acute and chronic effects of cigarette smoking on arterial stiffness," Blood Pressure, vol. 14, no. 2, pp. 80-85, 2005.

[34] T. S. Bowman, J. M. Gaziano, J. E. Buring, and H. D. Sesso, “A prospective study of cigarette smoking and risk of incident hypertension in women," Journal of the American College of Cardiology, vol. 50, no. 21, pp. 2085-2092, 2007.

[35] R. O. Halperin, J. Michael Gaziano, and H. D. Sesso, "Smoking and the risk of incident hypertension in middle-aged and older men," American Journal of Hypertension, vol. 21, no. 2, pp. 148-152, 2008.

[36] A. Leone, "Smoking and hypertension," Journal of Cardiology and Current Research, vol. 2, no. 2, p. 57, 2015.

[37] M. Jura and L. P. Kozak, "Obesity and related consequences to ageing," Age, vol. 38, no. 1, 2016.

[38] V. Hirani, P. Zaninotto, and P. Primatesta, "Generalised and abdominal obesity and risk of diabetes, hypertension and hypertension-diabetes co-morbidity in England," Public Health Nutrition, vol. 11, no. 5, pp. 521-527, 2008.

[39] S. M. Abebe, Y. Berhane, A. Worku, and A. Getachew, "Prevalence and associated factors of hypertension: a crossectional community based study in northwest Ethiopia," PLoS One, vol. 10, no. 4, p. 11, Article ID e0125210, 2015.

[40] A. K. Shujaa and W. Nammas, "Khat chewing and cardiovascular risk profile in a cohort of yemeni patients with angiographically documented coronary artery disease," Heartasia, vol. 4, no. 1, pp. 164-167, 2012. 